\title{
FACTORS AFFECTING NURSES’ COMPLIANCE IN IMPLEMENTING STANDARD PRECAUTIONS IN GOVERNMENT HOSPITAL IN YOGYAKARTA
}

\author{
Rina Wijayanti Sagita ${ }^{1}$, Heny Suseani Pangastuti², Syahirul Alim ${ }^{3}$ \\ ${ }^{1}$ Government Hospital in Yogyakarta \\ ${ }^{2}$ Departement of Medical Surgical Nursing, Faculty of Medicine, Public Health and Nursing UGM \\ ${ }^{2}$ Departement of Basic and Emergency Nursing, Faculty of Medicine, Public Health and Nursing UGM \\ e-mail: rina.wijayanti.sagita@mail.ugm.ac.id
}

\begin{abstract}
Introduction: Nosocomial infection is infections that occur in patients when they are hospitalized. Data in several countries find that hundred millions of patients worldwide are exposed to nosocomial infection each year. Standard precautions are applied to prevent infections in the hospital. The results of observations and interviews on nurses at Government Hospital, Yogyakarta find non-compliance of nurses in implementing standard precautions. The study knowing factors affecting nurses' compliance in Government Hospital, Yogyakarta. Methode: The study was conducted in June-July 2018 using cross-sectional study design. Data were obtained by observing and filling out questionnaires on 103 nurses in inpatient wards. This study used 19 questionnaires according to the variables studied. Data analysis using linear regression. Result: Nursing compliance with standard precautions calculated for 14, $56 \%$. Variables affecting compliance to standard precautions included motivation with $\mathrm{p}-$ value: 0,003 and work experience with $p$-value: 0,013 . These two variables affected standard precautions by $16,2 \%$. The dominant variable influencing compliance to standard precautions is motivation. Conclusions: Nursing compliance with standard precautions calculated for 14, $56 \%$. Variables affecting compliance to standard precautions included motivation and work experience. The dominant variable affecting compliance to standard precautions is motivation.
\end{abstract}

Key words : word compliance with standard precaution, factors affecting nurses' compliance

\section{PENDAHULUAN}

Infeksi nosokomial adalah infeksi yang terjadi pada pasien ketika pasien di rawat di rumah sakit. Infeksi nosokomial meliputi infeksi central line, infeksi saluran urinaria, infeksi area operasi dan pneumonia (Khan et al., 2017). Data di sejumlah negara ditemukan bahwa ratusan juta pasien di seluruh dunia terkena infeksi nosokomial setiap tahun (WHO, 2018). 100 pasien yang dirawat di rumah sakit, 10 pasien terkena infeksi nosokomial di negara berkembang dan 7 pasien terkena infeksi nosokomial di negara maju (WHO, 2018). Infeksi nosokomial di negara berkembang 2-6x lebih banyak dibandingkan di negara maju (Raka and Osmani, 2012).

Faktor-faktor yang berpengaruh dalam insidensi infeksi nosokomial di rumah sakit meliputi keluarga, penderita lain, makanan/minuman yang disajikan, lingkungan peralatan medis dan petugas pelayanan medis. Dokter, perawat, tenaga laboratorium, tenaga kesehatan lainnya dapat menyebarkan atau terkena infeksi nosokomial (Darmadi, 2008). Berdasarkan studi yang dilakukan oleh Luo et al., (2010) didapatkan hasil bahwa pada tahun 2002 di Amerika Serikat ditemukan 57 tenaga kesehatan terinfeksi HIV yang disebabkan oleh paparan rumah sakit, 24 orang diantaranya perawat dan 48 tenaga kesehatan lainnya terkena infeksi karena tertusuk alat-alat kesehatan.

Menyikapi banyaknya infeksi nosokomial yang terjadi dan untuk melindungi pasien dan tenaga kesehatan, Centers for Disease Control 
and Prevention (CDC) menetapkan standard precautions pada tahun 1996 sebagai petunjuk atau acuan dalam usaha mengurangi resiko infeksi dari darah yang terpercik dan patogen lain di rumah sakit (Luo et al., 2010). Peningkatan upaya pengendalian infeksi untuk melindungi pasien, pengunjung dan tenaga kesehatan juga menjadi perhatian di Indonesia (Depkes RI, 2008).

Hasil observasi oleh peneliti pada perawat di bangsal ditemukan bahwa perawat tidak mencuci tangan dengan menggunakan gel alkohol ketika berpindah ke pasien yang lain, yang tidak memakai sarung tangan ketika melakukan penyuntikan ke pasien dan melakukan infus ke pasien dengan vena yang sulit dicari.

Wawancara peneliti dengan perawat di bangsal IGD dan sebagian bangsal rawat inap di RS Pemerintah Yogyakarta terkadang perawat tidak memakai sarung tangan pada saat memasang infus pasien dengan alasan vena yang susah dicari, ketersediaan sarung tangan habis, saat memasang infus anak dan saat menyuntik insulin. Selain itu juga terdapat praktik menyuntik yang tidak aman yaitu melakukan recapping jarum suntik. Kejadian perawat yang tertusuk jarum pada tahun 2016 sebanyak 16 kasus dan pada bulan Januari-Agustus 2017 ditemukan kasus perawat yang tertusuk jarum ketika melakukan tindakan ke pasien sebanyak 6 kasus (Data Tim PPI RS Pemerintah Yogyakarta, 2016/2017).

Berdasarkan uraian latar belakang diatas, peneliti tertarik untuk mengetahui faktor apa sajakah yang mempengaruhi kepatuhan perawat dalam melaksanakan kewaspadaan standar di RS Pemerintah Yogyakarta.

\section{METODE}

Penelitian ini merupakan penelitian kuantitatif dengan menggunakan pendekatan cross sectional untuk mengetahui faktorfaktor yang mempengaruhi kepatuhan perawat terhadap kewaspadaan standar. Jumlah sampel dalam penelitian ini sebanyak 103 perawat RS Pemerintah Yogyakarta. Teknik penelitian sampling dengan menggunakan total sampling. Data dianalisis bivariate untuk diikutsertakan dalam analisis multivariate regresi linier.

\section{HASIL}

\section{Karakteristik responden}

Karakteristik responden dapat dilihat pada tabel di bawah ini:

\begin{tabular}{lccccc}
\hline \multicolumn{1}{c}{ Karakteristik } & f & \% & Min & Max & Mean \pm SD \\
\hline Jenis Kelamin & 12 & $11,65 \%$ & & \\
Laki-laki & 91 & $88,35 \%$ & & \\
Perempuan & & & & \\
\hline Pendidikan & 99 & $96,11 \%$ & & \\
D3 & 4 & $3,89 \%$ & & \\
S1 Ners & 43 & $41,75 \%$ & & \\
\hline Pengalaman bekerja & 60 & $58,25 \%$ & & \\
$<5$ tahun & & & 23 & 50 & $29,57 \pm 4,928$ \\
$\geq 5$ tahun & 103 & $100 \%$ & & & \\
\hline Umur & & & & \\
\hline Total & & & & \\
\hline
\end{tabular}

Tabel 1. Tabel 1. Karakteristik Perawat yang Bekerja di RS Pemerintah Yogyakarta bulan Juni-Juli 2018 (103) 
Tabel 1. Menunjukkan bahwa sebagian besar perawat mempunyai jenis kelamin perempuan sebanyak 91 responden $(88,35 \%)$ dan pendidikan paling banyak adalah D3 sebanyak 99 responden (96,11\%). Pengalaman bekerja paling banyak yaitu $\geq 5$ tahun sebanyak 60 responden $(58,25 \%)$. Umur perawat terendah 23 tahun dan tertinggi 50 tahun.

\section{Kepatuhan kewaspadaan standar}

Berikut ini hasil kepatuhan kewaspadaan standar yang dilakukan oleh perawat di RS Pemerintah di Yogyakarta. Responden dalam kepatuhan kewaspadaan standar sebanyak 103 perawat.

\begin{tabular}{|c|c|c|c|c|c|}
\hline \multirow{3}{*}{ Bangsal } & \multicolumn{4}{|c|}{$\begin{array}{c}\text { Jumlah Perawat Yang Melaksanakan Kepatuhan } \\
\text { terhadap Kewaspadaan Standar }\end{array}$} & \multirow{3}{*}{$\begin{array}{l}\text { Jumlah Total } \\
\text { Perawat }\end{array}$} \\
\hline & \multicolumn{2}{|c|}{$\mathbf{Y a}$} & \multicolumn{2}{|c|}{ Tidak } & \\
\hline & $\mathbf{f}$ & $\%$ & $\mathbf{f}$ & $\%$ & \\
\hline WK & 0 & $0 \%$ & 11 & $10,6 \%$ & $11(10,6 \%)$ \\
\hline $\mathrm{A}$ & 0 & $0 \%$ & 10 & $9,8 \%$ & $10(9,8 \%)$ \\
\hline B & 0 & $0 \%$ & 8 & $7,8 \%$ & $8(7,8 \%)$ \\
\hline $\mathrm{C}$ & 4 & $3,8 \%$ & 6 & $5,8 \%$ & $10(9,7 \%)$ \\
\hline $\mathrm{D}$ & 2 & $2,2 \%$ & 7 & $6,8 \%$ & $9(8,7 \%)$ \\
\hline $\mathrm{E}$ & 4 & $3,8 \%$ & 9 & $87 \%$ & $13(12,6 \%)$ \\
\hline $\mathrm{F}$ & 4 & $3,8 \%$ & 6 & $5,8 \%$ & $10(9,7 \%)$ \\
\hline $\mathrm{G}$ & 0 & $0 \%$ & 13 & $12,6 \%$ & $13(12,6 \%)$ \\
\hline $\mathrm{K}$ & 1 & $0,96 \%$ & 10 & $9,7 \%$ & $11(10,7 \%)$ \\
\hline $\mathrm{M}$ & 0 & $0 \%$ & 8 & $7,8 \%$ & $8(7,8 \%)$ \\
\hline Total & 15 & $14,56 \%$ & 88 & $85,44 \%$ & $103(100 \%)$ \\
\hline
\end{tabular}

Tabel 2. Kepatuhan Perawat Terhadap Kewaspadaan Standar per Bangsal Bulan Juni Juli 2018 (n: 103)

\begin{tabular}{lcc}
\hline \multicolumn{1}{c}{ Kategori } & $\mathbf{r}$ & $\mathbf{p}$ \\
\hline Umur & $-0,076$ & 0,0446 \\
\hline Jenis kelamin & & 0,032 \\
\hline Tingkat pendidikan & 0,151 & 0,128 \\
\hline Sikap & 0,171 & 0,085 \\
\hline Pengetahuan tentang kewaspadaan standar & 0,215 & 0,029 \\
\hline Pengetahuan tentang infeksi & $-0,036$ & 0,719 \\
\hline Motivasi & 0,358 & 0,000 \\
\hline Pengalaman kerja & $-0,226$ & 0,022 \\
\hline Persepsi terhadap risiko & $-0,017$ & 0,868 \\
\hline Efikasi pencegahan & 0,000 & 0,998 \\
\hline Risk taking personality & $-0,142$ & 0,152 \\
\hline Pengalaman tertusuk jarum & $-0,140$ & 0,160 \\
\hline Beban kerja & 0,026 & 0,795 \\
\hline Stres kerja & $-0,014$ & 0,885 \\
\hline Hambatan dalam pelaksanaan kewaspadaan & 0,147 & 0,139 \\
standar & & \\
\hline Kesediaan APD & $-0,093$ & 0,352 \\
\hline Pelatihan & 0,186 & 0,061 \\
\hline Safety climate & 0,66 & 0,093 \\
\hline Safety performance feedback & $-0,009$ & 0,931 \\
\hline
\end{tabular}

Tabel 3. Uji Kandidat Faktor Kepatuhan terhadap Kewaspadaan Standar dengan Karakteristik Responden di Bangsal Rawat Inap RS Pemerintah Yogyakarta bulan Juni Juli 2018 (n:103) 
Tabel 2. menunjukkan bahwa kepatuhan perawat dalam melaksanakan kewaspadaan standar sebesar 14, $56 \%$, sedangkan ketidakpatuhan perawat dalam melaksanakan kewaspadaan standar sebesar $85,44 \%$.

\section{F a k t or - faktor y a $\mathrm{g}$ mempengaruhi kepatuhan perawat dalam melaksanakan kewaspadaan standar}

Faktor-faktor yang mempengaruhi kepatuhan perawat dalam melaksanakan kewaspadaan standar dapat dilihat pada tabel 3. Tabel ini menunjukkan variabel yang memenuhi uji kandidat untuk analisis multivariat dengan nilai $\mathrm{p}<0,25$ meliputi jenis kelamin dengan nilai p: 0,032, tingkat pendidikan dengan nilai p: 0,128 , sikap dengan nilai p: 0,085, pengetahuan tentang kewaspadaan standar dengan nilai p: 0,029, motivasi dengan nilai p: 0,000, pengalaman kerja dengan nilai p: 0,022, risk taking personality dengan nilai p: 0,152 , pengalaman tertusuk jarum dengan nilai p: 0,160 , hambatan dalam pelaksanaan kewaspadaan standar dengan nilai p: 0,139 , pelatihan dengan nilai $\mathrm{p}: 0,061$ serta safe climate dengan nilai p: 0,093.

\section{Faktor-faktor dominan yang mempengaruhi kepatuhan perawat dalam melaksanakan kewaspadaan standar}

Berikut ini hasil uji regresi linier dari 11 variabel yang memenuhi syarat dilakukan analisis multivariat. Dua variabel mempunyai hubungan bermakna terhadap kepatuhan kewaspadaan standar.

Tabel 4. Menunjukkan bahwa motivasi dan pengalaman kerja memberikan pengaruh 16, $2 \%$ terhadap kepatuhan kewaspadaan standar, sedangkan 83, $8 \%$ kepatuhan kewaspadaan standar dipengaruhi oleh faktor lain.

\begin{tabular}{|c|c|c|c|c|c|}
\hline \multirow[t]{2}{*}{ Model } & \multicolumn{2}{|c|}{$\begin{array}{l}\text { Unstandarized } \\
\text { Coefficients }\end{array}$} & \multirow{2}{*}{$\begin{array}{c}\text { Standarized } \\
\text { Coefficients } \\
\text { Beta }\end{array}$} & \multirow[t]{2}{*}{$\mathbf{T}$} & \multirow[t]{2}{*}{ Sig } \\
\hline & B & Std. Error & & & \\
\hline Constant & 10,377 & 2,610 & & 3,976 & 0,000 \\
\hline Jenis Kelamin & $-0,402$ & 0,282 & $-\quad 0,144$ & $-1,424$ & 0,158 \\
\hline $\begin{array}{l}\text { Tingkat } \\
\text { Pendidikan }\end{array}$ & 0,438 & 0,474 & 0,091 & 0,925 & 0,358 \\
\hline Sikap & 0,021 & 0,051 & 0,042 & 0,416 & 0,678 \\
\hline Motivasi & 0,079 & 0,026 & 0,353 & 3,058 & 0,003 \\
\hline $\begin{array}{l}\text { Pengalaman } \\
\text { Kerja }\end{array}$ & $-0,060$ & 0,023 & $-\quad 0,250$ & $-2,543$ & 0,013 \\
\hline $\begin{array}{l}\text { Risk Taking } \\
\text { Personality }\end{array}$ & $-0,116$ & 0,086 & 0,154 & $-1,346$ & 0,182 \\
\hline $\begin{array}{l}\text { Pengalaman } \\
\text { Tertusuk }\end{array}$ & 0,302 & 0,248 & 0,113 & $-\quad 1,217$ & 0,227 \\
\hline Hambatan KS & 0,008 & 0,048 & 0,017 & 0,157 & 0,876 \\
\hline Pelatihan & 0,087 & 0,305 & 0,030 & 0,286 & 0,776 \\
\hline Safety Climate & $-0,005$ & 0,028 & 0,023 & $-0,192$ & 0,848 \\
\hline
\end{tabular}

Tabel 4. Faktor-Faktor Yang Dominan Mempengaruhi Kepatuhan Perawat Terhadap Kewaspadaan standar di Bangsal Rawat Inap RSUD Wates bulan Juni - Juli 2018 (n:103) 


\section{PEMBAHASAN}

Motivasi adalah derajat kerelaan individu dalam menggunakan dan memelihara upaya untuk mencapai tujuan perusahaan. Motivasi berpengaruh terhadap efektifitas dan produktivitas sehingga meningkatkan kinerja (Franco et al., 2004 cit Riniwati, 2016). Sumber motivasi yang paling utama adalah intrinsik dan ekstrinsik (Devoe and Lyengar, 2004 cit Riniwati, 2016). Motivasi intrisik adalah motivasi yang berasal dari dalam diri. Jika manusia menggunakan ketrampilan dalam bekerja, membuat keputusan, belajar ketrampilan baru maka kapasitas intelektual dan kepuasan hidup akan tumbuh (Paul et al., 2000 cit Riniwati, 2016). Sedangkan motivasi ekstrinsik adalah perilaku yang dibentuk untuk kebutuhan berkaitan dengan materi dan penghargaan meliputi upah yang tinggi, keamanan kerja, keuntungan kerja, status dan kontak sosial (George and Jones, 2002 cit Riniwati, 2016).

Hasil penelitian yang dilakukan menunjukkan ada hubungan signifikan antara motivasi dengan kepatuhan terhadap kewaspadaan standar. Sebanding dengan penelitian yang dilakukan oleh Kusworo (2014) yang menyatakan ada hubungan signifikan antara motivasi dengan kepatuhan terhadap kewaspadaan standar. Motivasi yang tinggi akan menaati kewaspadaan standar, sedangkan motivasi yang rendah tidak melakukan kewaspadaan standar. Penelitian yang dilakukan Ganta (2014) juga menemukan ada hubungan motivasi dengan performance dan produktifitas pekerja. Penghargaan untuk pekerja akan meningkatkan proses belajar dan kemajuan bagi pekerja.

Penelitian ini menunjukkan bahwa motivasi yang tinggi akan menaati kepatuhan terhadap kewaspadaan standar, sedangkan motivasi yang rendah tidak menaati kepatuhan terhadap kewaspadaan standar. Faktor motivasi berasal dari perawat sendiri dalam melakukan pelayanan ke pasien. Motivasi dan kepatuhan merupakan hal yang berbanding lurus dalam arti semakin tinggi motivasi yang ada di dalam diri perawat, maka akan semakin tinggi pula tingkat kepatuhannya (Dewantara, 2016).

Pengalaman kerja adalah aktifitas yang dibayar ataupun yang tidak dibayar yang dapat meningkatkan ketrampilan pekerja. Pengalaman kerja dapat meningkatkan karier pekerja (Rook, 2016). Hasil penelitian ini menemukan ada hubungan pengalaman kerja dengan kepatuhan terhadap kewaspadaan standar. Penelitian dengan variabel yang sama juga dilakukan oleh Runtu (2012), Sarani et al. (2016) serta Aung et al. (2017) yang menemukan bahwa tidak ada hubungan pengalaman kerja dengan kepatuhan terhadap kewaspadaan standar.

Penelitian yang dilakukan oleh peneliti sebanding dengan penelitian Mc Govern et al. (2000) yang menyatakan ada hubungan antara pengalaman kerja dengan kepatuhan terhadap kewaspadaan standar. Hasil penelitian Govern et al. (2000) menunjukkan bahwa petugas kesehatan yang telah bekerja 5 tahun atau lebih 1,7 kali lebih mungkin patuh menerapkan universal precautions daripada mereka yang bekerja kurang dari 5 tahun.

Rata-rata masa kerja dalam penelitian yang dilakukan oleh peneliti adalah 5 tahun 3 bulan. Penelitian yang dilakukan Cates (2011) yang menyatakan bahwa masa kerja, seseorang akan mendapat pelajaran bagaimana ia dapat bekerja dengan baik, efisien dan aman.

Variabel yang mempunyai pengaruh terhadap kepatuhan kewaspadaan standar meliputi motivasi dan pengalaman kerja. Variabel yang paling dominan berpengaruh terhadap kepatuhan kewaspadaan standar adalah motivasi. Penelitian Kusworo (2014) menyebutkan ada hubungan motivasi dengan kepatuhan terhadap kewaspadaan standar. 
Seseorang termotivasi dengan baik agar mencapai tujuan dari organisasi. Apabila seseorang semakin termotivasi maka akan lebih berkomitmen dan dapat mengidentifikasi peran di organisasi tersebut. Peran pimpinan dalam memberikan motivasi kepada pekerja sangat dibutuhkan terkait tujuan bersama dan insentif (Shanks, 2012 cit Burton, 2012).

RSUD adalah rumah sakit milik pemerintah yang berada di Yogyakarta. Perawat mempunyai komitmen bersama-sama memberikan pelayanan paripurna kepada pasien. Motivasi perawat berasal dari dalam dan luar. Motivasi dalam berasal dari diri yang ingin bekerja sesuai dengan yang diharapkan organisasi. Motivasi dari luar berasal dari pemberian insentif dan dukungan manager untuk selalu termotivasi dalam bekerja, terutama kepatuhan terhadap prosedur.

Peneliti menemukan motivasi dan pengalaman kerja mempengaruhi kepatuhan perawat dalam melaksanakan kepatuhan standar. Faktor lain yang mempengaruhi kepatuhan perawat terhadap kewaspadaan standar meliputi persepsi kelengkapan sarana prasarana, persepsi kemampuan diri, komitmen managemen, informasi, kepercayaan, nilai, peer review, kemampuan kognitif, tipe RS, ketersediaan box benda tajam, kepemimpinan serta supervisi (Runtu, 2012; Purnomo, 2015; Mc Govern et al., 2000; Luo et al., 2000; Sukriani, 2013).

\section{KESIMPULAN}

Kepatuhan perawat dalam melaksanakan kewaspadaan standar sebesar 14, 56 \%. Faktor yang mempengaruhi kepatuhan perawat terhadap kewaspadaan standar meliputi motivasi dan pengalaman kerja. Faktor yang paling dominan mempengaruhi kewaspadaan standar adalah motivasi.

\section{DAFTAR PUSTAKA}

Aung, S.S., Nursalam., Dewi, Y.S., (2017). Factor affecting the compliance of Myanmar nurses in performing standard precautions. Journal Ners 12(1):1-8.

Burton, K., (2012). A study of motivation: how to get your employees moving. Thesis: Indiana University.

Darmadi., (2008). Infeksi Nosokomial: Problematika dan Pengendaliannya. Jakarta: Salemba Medika.

Depkes RI., (2008). Pedoman Pencegahan dan Pengendalian Infeksi di Rumah Sakit dan Fasilitas Pelayanan Kesehatan Lainnya: Kesiapan Menghadapi Emerging Infectious Disease Cetakan kedua. Jakarta.

Dewantara., (2016). Hubungan motivasi kerja dengan kepatuhan penggunaan alat pelindung diri pada perawat di ruang rawat inap Rumah Sakit Paru Jember.http://repository.unej.ac.id/ bitstream/handle/123456789/76414/ Bima\%Satriya\%20Dewantara\%20-1/ pdf?sequence: 1 .

Ganta, V.C., (2014). Motivation in the workplace to improve the employee performance. International Journal of Engineering Technology, Management and Applied Sciences 2(6): 221-230.

Khan, H.A., Baig, F.K., Mehboob, R., (2017). Nosocomial infection: epidemiology, prevention, control and surveillance. Asian Pasific Journal of Tropical Biomedicine, 7(5), 476-482.

Kusworo, W.S., (2014). Hubungan motivasi dengan penerapan universal precaution di bangsal bedah dan penyakit dalam kelas 3 RSUD Muntilan Kabupaten Magelang. Skripsi: Stikes Aisyiah Yogyakarta.

Luo, Y., He, G.P., Zhou, J.W., Luo, Y., (2010). Factors impacting compliance with standar precautions in nursing Cina. International Journal of Infectious Disease, 14:1106-1114.

McGovern, P.M., Vesley, D., Kochevar, L., Gershon, R.R., (2000). Factor affecting universal precautions compliance. Journal of Business and Psychology, 15(1): 149161.

Purnomo, R., (2015). Analisis faktor-faktor yang berhubungan dengan kepatuhan perawat pelaksana dalam penerapan standar precautions di RSUD Banyumas. Tesis: Universitas Diponegoro Semarang.

Raka, L and Osmani, G.M., (2012). Infection Control in Developing World. www.cdn. intechopen.

Riniwati, Harsuko. 2016. Manajemen Sumberdaya Manusia: Aktivitas Utama dan Pengembangan SDM. Malang: UB Press.

Rook, S., (2016). Work Experience, Lacements and Interships. London: Palgrave. 
Runtu, L.G., (2012). Faktor-faktor yang berhubungan dengan perilaku perawat dalam penerapan universal precautions di RSUP.Prof.Dr.D.Kandau, Manado. Tesis: Universitas Gadjah Mada.

Sarani, H., Balochi, A., Masinaeninezhad, N., Ebrabimitabs, E., (2016). Knowledge, attitude and practice of nurses about standard precautions for hospital acquired infection in teaching hospitals affilated to Zabol University of Medical
Sciences. Global Journal of Health Science, 8 (3).

Sukriani., (2013). Hubungan faktor organisasi dengan pelaksanaan kewaspadaan universal oleh perawat di rawat inap RSUP.Dr.Wahidin Sudirohusodo. Makasar.

WHO., (2018). Health Care Associated Infections Fact Sheet. www.who.int/gpsc/country/ gpsc_ccisc_fact_sheet_en.pdf. 